\title{
Evaluation and comparison of haemodynamic response and ease of intubation between Truview PCD TM, McCOY and Macintosh laryngoscope blades
}

\author{
Alka Chandra ${ }^{*}$, Manish Singh², Megha Agarwal $^{3}$, Rashmi Duggal $^{4}$, Dheeraj Gupta ${ }^{5}$ \\ ${ }^{1}$ Senior Specialist, ${ }^{2}$ Student, ${ }^{3}$ Medical Officer, ${ }^{4} \mathrm{HOD},{ }^{5} \mathrm{CMO}$, Dept. of Anaesthesiology and Critical Care, ${ }^{\mathbf{1}, 2,4,5}$ Hindurao Hospital, New \\ Delhi, ${ }^{3}$ NDMC Medical College and Hindurao Hospital, New Delhi, India
}

*Corresponding Author: Alka Chandra

Email: dralkadelhi@yahoo.co.in

Received: $15^{\text {th }}$ February, 2019

Accepted: $5^{\text {th }}$ April, 2019

\begin{abstract}
Introduction: Failure to secure the airway can lead to adverse cardiopulmonary events, brain damage or even anaesthetic death. The advent of various optical or video laryngoscopes have brought about a revolution in airway management. Truview $\mathrm{PCD}^{\mathrm{TM}}$ laryngoscope is a recently introduced device with a unique blade and prismatic lens which without external manipulation makes visualization of laryngeal inlet much easier. We have therefore compared glottic visualization haemodynamic response and ease of intubation between Truview $\mathrm{PCD}^{\mathrm{TM}}$, McCoy and Macintosh laryngoscope blades.

Material and Methods: Patients were randomly allocated into three groups of 40 each. Group I-Truview PCD ${ }^{\mathrm{TM}}$ laryngoscope, group IIMcCoy laryngoscope and group III- Macintosh laryngoscope group. After induction patients were intubated with appropriate blade according to the group allocated. Visualization of laryngeal inlet was graded using Modified Cormack and lehane. Ease of intubation was also graded and hemodynamic parameters were noted on following occasions. Baseline (T1), before induction (T2), after induction (T3), immediately after intubation (T4), $1 \mathrm{~min}, 3 \mathrm{~min}$ and $5 \mathrm{~min}$ after intubation (T5,T6 and T7 respectively).

Result: Quantitative variables were co-related using ANOVA/Kruskal Wallis test between the three groups and post hoc comparison was performed by independent $\mathrm{T}$ test/ Mann-Whitney test (when the data sets were not normally distributed) between the two groups. Qualitative variables were correlated using Chi-square test/Fisher's exact test. The data was entered in MS EXCEL spreadsheet and analysis was done using Statistical Package for Social Sciences (SPSS) version 21.0 (Chicago, USA). A P-value of $<0.05$ was considered statistically significant.

There was a difference in visualization of glottis which was statistically significant between the three groups $(\mathrm{P}<0.0001)$. The view was best in group I compared to group II \& III ( $\mathrm{P}=0.024, \mathrm{P}<0.0001$ respectively). The view was however better in group II compared to group III $(\mathrm{P}<0.0001)$. The time for intubation was more in group I compared to group II $(\mathrm{P}<0.0001)$ and group III $(\mathrm{P}<0.0001)$. However it was more in group II compared to group III $(\mathrm{P}<0.0001)$. The number of attempts for intubation and need for the change of blade was comparable in all the three groups $(\mathrm{P}=\mathrm{NS})$. The heart rate was higher in group I compared to group II at T4, 5, $6 \& 7$ ( $\mathrm{P}<0.0001, \mathrm{P}<0.0001$, $\mathrm{P}<0.0001 \& \mathrm{P}<0.0001$ respectively). However compared to group III it was comparable at $\mathrm{T} 4,5,6 \& 7(\mathrm{P}=0.709, \mathrm{P}=0.221, \mathrm{P}=0.170$, $\mathrm{P}=0.748$ respectively). Compared to group II the heart rate was higher in group III at T4, 5, 6, \& $7(\mathrm{P}<0.0001, \mathrm{P}<0.0001, \mathrm{P}<0.0001$, $\mathrm{P}<0.0001$ respectively). The mean arterial pressure was higher in group I compared to group II at $\mathrm{T} 4,5,6,7$ ( $\mathrm{P}<0.0001, \mathrm{P}<0.0001$, $\mathrm{P}<0.0001, \mathrm{P}<0.0001$ respectively), it was also higher than in group III at $\mathrm{T} 4,5$ \& 6 except at $\mathrm{T} 7(\mathrm{P}=0.0007, \mathrm{P}<0.0001, \mathrm{P}<0.0001, \mathrm{P}=0.521$ respectively). Compared to group II the MAP was higher in group III at $\mathrm{T} 4,5,6, \&$ $7(\mathrm{P}<0.0001, \mathrm{P}<0.0001, \mathrm{P}<0.0001, \mathrm{P}<0.0001$ respectively.

Conclusion: Truview PCD TM laryngoscope blade can be used in difficult airway situation to visualize glottis. The time taken to intubate is longer and failure rate is slightly higher which can however be reduced by proper training, experience and increased hand eye coordination.
\end{abstract}

Keywords: Laryngoscopes, Airway management, Anaesthesia, Arterial pressure.

\section{Introduction}

Unanticipated or anticipated difficult airway is a challenge which anaesthesiologist has to face in securing the airway. ${ }^{1}$ Brain damage or anaesthetic death although infrequent are the most dreaded complications of tracheal intubation. ${ }^{2}$ Hypertension, tachycardia, dysrhythmia, myocardial ischemia, increased circulating catecholamines and cerebral haemorrhage are some of the complications associated with laryngoscopy and intubation. ${ }^{3}$ Many cases of difficult intubation are missed even after doing a preoperative assessment of airway. Visualizing larynx or passing endotracheal tube into glottis are the problems encountered frequently while doing tracheal intubation. ${ }^{4}$

The glottic view during laryngoscopy can be classified using Modified Cormack Lehane grading or percentage of glottic opening (POGO). The bedside prediction of the preoperative risk of difficult intubation can be done by Mallampati test, which has a reported sensitivity of $50 \%$ and specificity of $90 \% .^{5-7}$ The view of glottis can be improved by external manipulation of larynx using either backwardupward-rightward pressure (BURP) or doing bimanual laryngoscopy. The number of attempts and need for external manipulation are the indicators of difficulty encountered during laryngoscopy and intubation. ${ }^{1}$

Macintosh curved laryngoscope blade invented in 1943 is the most popular device use for orotracheal intubation and constitutes a gold standard. ${ }^{8}$ The McCoy blade is a modification of the standard Macintosh blade with a hinge at tip to avoid lifting force in the valeculla and facilitate tracheal intubation. ${ }^{9}$ Truview PCD ${ }^{\mathrm{TM}}$ laryngoscope 
(Truphatek International Ltd, Netanya, Israel) is a recently introduced device with a unique blade and prismatic lens which makes visualization of laryngeal inlet easier without need of much external manipulation. ${ }^{4}$ In a study done using Truview the laryngeal view was consisitenly improved as compared to Macintosh blade without need to align the oral, pharyngeal and tracheal axis with equal attempts for successful intubation and similar changes in haemodynamics, but the time taken for intubation was more. ${ }^{10}$

In the present study we have tried to evaluate and compare glottic visualization, time for intubation, number of attempts and haemodynamic response between Truview $\mathrm{PCD}^{\mathrm{TM}}$, McCoy and Macintosh laryngoscope blades.

\section{Materials and Methods}

After taking written consent and obtaining institutional ethical committee approval 120 patients of the American Society of Anaesthesiologist (ASA) physical status I and II, aged 18-60yrs with MP grade I and II scheduled for elective surgery under general anaesthesia from June 2016 to June 2018 were enrolled in the study. All patients were randomly divided into three groups of 40 each using an online research randomizer (http://www.randomizer.org) to be intubated with the specific laryngoscope blade allocated according to the group. Group I-Truview PCD TM laryngoscope group. Group II- McCOY laryngoscope group and group III- Macintosh laryngoscope group. ASA grade III, IV, MMPC III or IV, patients with, hepatic, renal, cardiopulmonary, ophthalmic or metabolic diseases were excluded from the study. All the patients received tablet ranitidine and tablet alprazolam $0.25 \mathrm{mg}$ night before surgery. Each patient was given injection metoclopromide $10 \mathrm{mg}$, midazolam $0.25 \mathrm{mg} / \mathrm{kg}$ and fentanyl $2 \mathrm{ugm} / \mathrm{kg}$ in the operation theatre. Anaesthesia was induced with injection propofol $2 \mathrm{mg} / \mathrm{kg}$ and injection vecuronium $0.1 \mathrm{mg} / \mathrm{kg}$. The patients were ventilated with $100 \%$ oxygen for 3 minutes and then intubated with appropriate blade according to the group. Visualization of the laryngeal inlet was graded using Modified Cormack Lehane Grade (MCLG). Grade 1complete glottis visible, Grade 2a-Partial view of glottis, Grade $2 b$ - Only posterior extremity of glottis seen or only arytenoid cartilages, Grade 3-Only epiglottis seen, none of the glottis seen, Grade 4- Neither glottis nor epiglottis seen. The ease of intubation (EOI) was graded as follows:

Grade 1- Intubation easy.

Grade 2- Intubation requiring an increased anterior lifting force and assistance to pull the right corner of the mouth upwards to increase the space.

Grade 3- Intubation requiring multiple attempts.

Grade 4- Failure to intubate with the assigned blade.

The haemodynamic parameters i.e heart rate and mean arterial pressure were recorded on following occasions.

Baseline (T1), Before induction (T2), After induction (T3), Immediately after intubation (T4), 1 minute after intubation (T5), 3 minute after intubation (T6), 5 minute after intubation.(T7). Maintanence and reversal of anaesthesia was done as per the standard protocol.

\section{Statistical Analysis}

Categorial variables were presented in number and percentage, continuous variables were presented as mean \pm SD and median. Normality of data was tested by Kolmogorov-Smirnov test. Quantitative variables were corelated using ANOVA/Kruskal Wallis test between the three groups and post hoc comparison was performed by independent $\mathrm{T}$ test/ Mann-Whitney test (when the data sets were not normally distributed) between the two groups. Qualitative variables were correlated using Chi-square test/Fisher's exact test. The data was entered in MS EXCEL spreadsheet and analysis was done using Statistical Package for Social Sciences (SPSS) version 21.0 (Chicago, USA). A $\mathrm{P}$-value of $<0.05$ was considered statistically significant.

\section{Sample Size}

With reference to study one using a two tailed alpha value $(0.05)$ and power $80 \%, 40$ observations per group was found sufficient to detect a significant difference of $30 \%$ between any two groups.

\section{Result}

The demographic data of the three groups were comparable as shown in Table 1. The ASA grade and MMPC grade amongst the three groups was also comparable $[\mathrm{P}=0.967$ and 0.967 respectively (NS)]. As shown in Table 2 the view of glottis was best in group I compared to group II and III $(\mathrm{P}<0.0001)$. The glottic view was better in group II compared to group III $(\mathrm{P}=0.036)$ but was better in group I compared to group II and group III $(\mathrm{P}=0.24$ and $\mathrm{P}<0.0001$ respectively). As shown in Table 3 the time for intubation was more in group I $(25.76 \pm 12.30$ seconds) compared to group II (17.18 \pm 6.31$)$ and III (14.08 \pm 4.92), $\mathrm{P}<0.0001$ and $\mathrm{P}<0.0001$ respectively. However in group II the time for intubation was statistically more than in group III. $(\mathrm{P}=0.001)$. As shown in Table 4 the heart rate was comparable in all the three groups at T1, $2 \& 3$ $(\mathrm{P}=0.939, \mathrm{P}=0.962, \mathrm{P}=0.989$ respectively). The heart rate was higher in group I compared to group II at T4, 5, $6 \& 7$ (P $(\mathrm{P}<0.0001, \mathrm{P}<0.0001, \mathrm{P}<0.0001 \& \mathrm{P}<0.0001$ respectively). However compared to group III it was comparable at T4, 5, $6 \& 7(\mathrm{P}=0.709, \mathrm{P}=0.221, \mathrm{P}=0.170, \mathrm{P}=0.748$ respectively). Compared to group II the heart rate was higher in group III at T4, 5, 6, \& $7(\mathrm{P}<0.0001, \mathrm{P}<0.0001, \mathrm{P}<0.0001, \mathrm{P}<0.0001$ respectively). As shown in Table 5 the mean arterial pressure was comparable between the three groups at $\mathrm{T} 1,2$, \& $3(\mathrm{P}=0.976, \mathrm{P}=0.942, \mathrm{P}=0.557$ respectively). The MAP was higher in group I compared to group II at T4, 5, 6, 7 $(\mathrm{P}<0.0001, \mathrm{P}<0.0001, \mathrm{P}<0.0001, \mathrm{P}<0.0001$ respectively), it was also higher than in group III at T4, $5 \& 6$ except at T7 $(\mathrm{P}=0.0007, \mathrm{P}<0.0001, \mathrm{P}<0.0001, \mathrm{P}=0.521$ respectively). Compared to group II the MAP was higher in group III at $\mathrm{T} 4,5,6, \& 7(\mathrm{P}<0.0001, \mathrm{P}<0.0001, \mathrm{P}<0.0001, \mathrm{P}<0.0001$ respectively. As shown in graph 1 the number of attempts in all the three groups was comparable $(\mathrm{P}=0.295$, NS). The need to change blade although higher in group I compared to group II and III it was not statistically significant $(\mathrm{P}=0.175, \mathrm{NS})$. 
Table 1: Demographic data of the three groups

\begin{tabular}{|l|c|c|c|c|}
\hline Demographic data & Group I & Group II & Group III & P Value \\
\hline Age $($ yrs) Mean \pm SD & $35 \pm 12.55$ & $37.1 \pm 10.25$ & $38 \pm 9.55$ & $0.392(\mathrm{NS})$ \\
\hline BMI & $21.89 \pm 1.02$ & $22.26 \pm 0.91$ & $22.01 \pm 0.77$ & $0.175(\mathrm{NS})$ \\
\hline Sex $(\%) \mathrm{M} / \mathrm{F}$ & $47.50 / 52.50$ & $50.0 / 50.0$ & $50.0 / 50.0$ & $0.967(\mathrm{NS})$ \\
\hline
\end{tabular}

Table 2: Comparison of glottis visualization between the three groups (MCLG)

\begin{tabular}{|c|c|c|c|c|c|c|c|c|}
\hline \multirow{2}{*}{ MCLG } & \multicolumn{3}{|c|}{ Group } & & \multirow{2}{*}{ p-value } & \multirow{2}{*}{ I vs II } & \multirow{2}{*}{ I vs III } & \multirow{2}{*}{ II vs III } \\
\hline & I & II & III & Total & & & & \\
\hline 1 & $32(80.00 \%)$ & $21(52.50 \%)$ & $9(22.50 \%)$ & $62(51.67 \%)$ & \multirow{5}{*}{$\begin{array}{c}<0.0001 \\
(\mathrm{~S})\end{array}$} & \multirow{5}{*}{$\begin{array}{c}0.024 \\
(\mathrm{~S})\end{array}$} & \multirow{5}{*}{$\begin{array}{c}<0.0001 \\
(\mathrm{~S})\end{array}$} & \multirow{5}{*}{$\begin{array}{c}0.036 \\
(\mathrm{~S})\end{array}$} \\
\hline $2 \mathbf{a}$ & $5(12.50 \%)$ & $5(12.50 \%)$ & $6(15.00 \%)$ & $16(13.33 \%)$ & & & & \\
\hline $2 b$ & $2(5.00 \%)$ & $8(20.00 \%)$ & $11(27.50 \%)$ & $21(17.50 \%)$ & & & & \\
\hline 3 & $1(2.50 \%)$ & $6(15.00 \%)$ & $14(35.00 \%)$ & $21(17.50 \%)$ & & & & \\
\hline 4 & $0(0.00 \%)$ & $0(0.00 \%)$ & $0(0.00 \%)$ & $0(0.00 \%)$ & & & & \\
\hline Total & \multicolumn{2}{|c|}{$40(100.00 \%)$} & $40(100.00 \%)$ & $40(100.00 \%)$ & $120(100.00 \%)$ & & & \\
\hline
\end{tabular}

S-Significant NS-Non significant

Table 3: Intergroup comparison of time for intubation between the three groups

\begin{tabular}{|c|c|c|c|c|c|c|c|}
\hline TTI & Group I & Group II & Group III & p-value & I vs II & I vs III & II vs III \\
\hline Sample size & 34 & 38 & 38 & \multirow{5}{*}{$\begin{array}{c}<0.0001 \\
(\mathrm{~S})\end{array}$} & \multirow{5}{*}{$\begin{array}{c}<0.0001 \\
(\mathrm{~S})\end{array}$} & \multirow{5}{*}{$\begin{array}{c}<0.0001 \\
(\mathrm{~S})\end{array}$} & \multirow{5}{*}{$\begin{array}{c}\mathbf{0 . 0 0 1} \\
(\mathbf{S})\end{array}$} \\
\hline Mean \pm SD & $25.76 \pm 12.30$ & $17.18 \pm 6.31$ & $14.08 \pm 4.92$ & & & & \\
\hline Median & 17.50 & 14 & 12 & & & & \\
\hline Min-Max & $14-48$ & $12-33$ & $10-33$ & & & & \\
\hline $\begin{array}{c}\text { Inter quartile } \\
\text { range }\end{array}$ & $16-34$ & $13-22$ & $11-15$ & & & & \\
\hline
\end{tabular}

Table 4: Intergroup comparison of heart rate changes between the three groups

\begin{tabular}{|c|c|c|c|c|c|c|c|}
\hline HR & $\begin{array}{c}\text { Group I } \\
\text { (Truveiw PCD }^{\text {TM }} \text { ) } \\
\text { Mean } \pm \text { SD }\end{array}$ & $\begin{array}{c}\text { Group II } \\
\text { (McCoy) } \\
\text { Mean } \pm \text { SD }\end{array}$ & $\begin{array}{c}\text { Group III } \\
\text { (Macintosh) } \\
\text { Mean } \pm \text { SD }\end{array}$ & p-value & $\begin{array}{c}\text { Group I } \\
\text { vs } \\
\text { Group II }\end{array}$ & $\begin{array}{c}\text { Group I } \\
\text { vs } \\
\text { Group III }\end{array}$ & $\begin{array}{c}\text { Group II } \\
\text { vroup III }\end{array}$ \\
\hline T1 & $79.80 \pm 10.04$ & $79.65 \pm 8.20$ & $79.12 \pm 8.44$ & 0.939 & 0.942 & 0.746 & 0.779 \\
\hline T2 & $78.82 \pm 9.35$ & $79.08 \pm 7.87$ & $78.55 \pm 7.97$ & 0.962 & 0.897 & 0.888 & 0.768 \\
\hline T3 & $78.82 \pm 8.78$ & $79.00 \pm 7.47$ & $78.72 \pm 8.31$ & 0.989 & 0.924 & 0.958 & 0.877 \\
\hline T4 & $99.55 \pm 8.21$ & $85.72 \pm 9.41$ & $100.22 \pm 7.89$ & $<\mathbf{0 . 0 0 0 1}$ & $<\mathbf{0 . 0 0 0 1}$ & 0.709 & $<\mathbf{0 . 0 0 0 1}$ \\
\hline T5 & $94.70 \pm 7.89$ & $82.32 \pm 9.17$ & $96.82 \pm 7.51$ & $<\mathbf{0 . 0 0 0 1}$ & $<\mathbf{0 . 0 0 0 1}$ & 0.221 & $<\mathbf{0 . 0 0 0 1}$ \\
\hline T6 & $89.02 \pm 6.65$ & $78.25 \pm 9.16$ & $91.22 \pm 7.53$ & $<\mathbf{0 . 0 0 0 1}$ & $<\mathbf{0 . 0 0 0 1}$ & 0.170 & $<\mathbf{0 . 0 0 0 1}$ \\
\hline T7 & $83.25 \pm 7.02$ & $74.35 \pm 7.57$ & $83.78 \pm 7.52$ & $<\mathbf{0 . 0 0 0 1}$ & $<\mathbf{0 . 0 0 0 1}$ & 0.748 & $<\mathbf{0 . 0 0 0 1}$ \\
\hline
\end{tabular}

Table 5: Intergroup comparison of mean arterial pressure (MAP) changes between the three groups

\begin{tabular}{|c|c|c|c|c|c|c|c|}
\hline MAP & $\begin{array}{c}\text { Group I } \\
\text { (Truveiw PCD }^{\text {TM}} \text { ) } \\
\text { Mean + SD }\end{array}$ & $\begin{array}{c}\text { Group II } \\
\text { (McCoy) } \\
\text { Mean } \pm \text { SD }\end{array}$ & $\begin{array}{c}\text { Group III } \\
\text { (Macintosh) } \\
\text { Mean } \pm \text { SD }\end{array}$ & p-value & $\begin{array}{c}\text { Group I } \\
\text { vs } \\
\text { Group II }\end{array}$ & $\begin{array}{c}\text { Group I } \\
\text { vs } \\
\text { Group III }\end{array}$ & $\begin{array}{c}\text { Group II } \\
\text { vs } \\
\text { Group III }\end{array}$ \\
\hline T1 & $92.47 \pm 7.25$ & $92.80 \pm 7.45$ & $92.50 \pm 7.55$ & 0.976 & 0.840 & 0.984 & 0.858 \\
\hline T2 & $92.13 \pm 7.12$ & $92.65 \pm 7.11$ & $92.20 \pm 7.57$ & 0.942 & 0.746 & 0.968 & 0.784 \\
\hline T3 & $79.03 \pm 7.14$ & $80.41 \pm 6.46$ & $80.67 \pm 8.20$ & 0.557 & 0.366 & 0.340 & 0.873 \\
\hline T4 & $117.57 \pm 8.13$ & $96.89 \pm 6.69$ & $122.66 \pm 8.25$ & $<\mathbf{0 . 0 0 0 1}$ & $<\mathbf{0 . 0 0 0 1}$ & $\mathbf{0 . 0 0 7}$ & $<\mathbf{0 . 0 0 0 1}$ \\
\hline T5 & $108.49 \pm 6.44$ & $92.84 \pm 5.94$ & $117.31 \pm 7.81$ & $<\mathbf{0 . 0 0 0 1}$ & $<\mathbf{0 . 0 0 0 1}$ & $<\mathbf{0 . 0 0 0 1}$ & $<\mathbf{0 . 0 0 0 1}$ \\
\hline T6 & $100.49 \pm 6.75$ & $88.58 \pm 5.48$ & $106.81 \pm 6.76$ & $<\mathbf{0 . 0 0 0 1}$ & $<\mathbf{0 . 0 0 0 1}$ & $<\mathbf{0 . 0 0 0 1}$ & $<\mathbf{0 . 0 0 0 1}$ \\
\hline T7 & $89.78 \pm 5.05$ & $84.68 \pm 4.62$ & $90.50 \pm 4.88$ & $<\mathbf{0 . 0 0 0 1}$ & $<\mathbf{0 . 0 0 0 1}$ & $\mathbf{0 . 5 2 1}$ & $<\mathbf{0 . 0 0 0 1}$ \\
\hline
\end{tabular}


Graph 1: Intergroup comparison of the number of attempts taken in each group

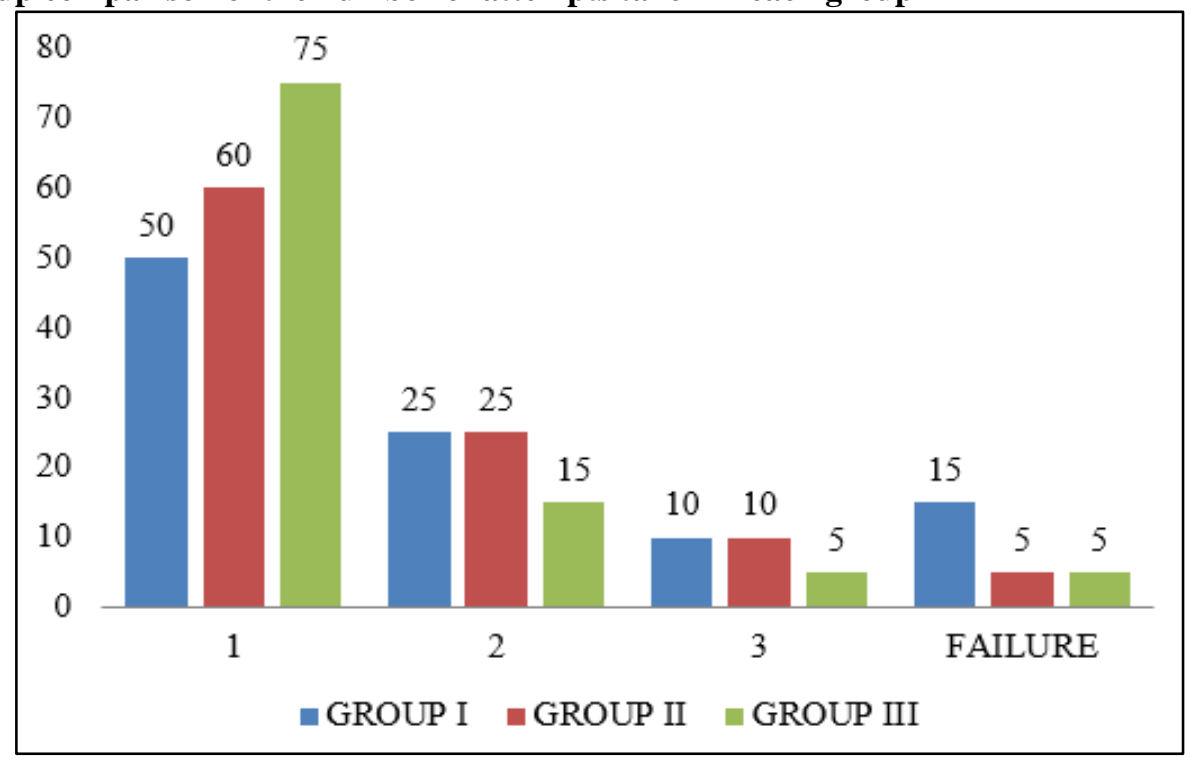

\section{Discussion}

Securing the airway with endotracheal tube by laryngoscopy and intubation is considered as a gold standard. Varieties of laryngoscopes have been developed over time to secure and maintain airway. The curved Macintosh blade is the most commonly used blade. Most popular staight blade is the Miller blade. It has been found that tracheal intubation is easier with the curved blades while glottis is viewed better with straight blades. ${ }^{11}$ The McCoy blade is a modification of the standard Macintosh blade with a hinge at tip to avoid lifting force in the vallecula and facilitate tracheal intubation. ${ }^{9}$ Truview $\mathrm{PCD}^{\mathrm{TM}}$ is an improved video laryngoscope. It consists of a stainless steel blade, a view tube, an oxygen insufflation port, a camera head which attaches to proximal part of the view tube, a handle that provides light source and a portable (5.5" battery-powered) monitor. The optical apparatus provides a $42^{\circ}$ angled deflection view through a $15 \mathrm{~mm}$ eyepiece. In limited neck extension the angle of view facilitates vision without any external laryngeal manipulation. The entry of tube device is specially designed to confirm positioning of the endotracheal tube as well as to record the entry of tube into glottis for research and archiving. In addition, its blade have a port that connects to auxillary oxygen source in anaesthesia machine which prevents misting, clears secretions from the lens and provides continuous oxygen insufflation during intubation. ${ }^{4}$

In the present study we have evaluated and compared glottis visualization, ease of intubation and haemodynamic response between Truview PCD ${ }^{\mathrm{TM}}$, McCoy and Macintosh blades. Kulkarni AP and Tirmanwar AS compared glottis visualization and ease of intubation with different laryngoscopic blades in 120 patients, divided into four groups of 30 each Macintosh, McCoy, Miller and Truview laryngoscope. Grade 1 view was obtained most often $(87 \%$ patients) with Trueview ${ }^{\circledR}$ laryngoscope. They concluded that glottis visualization is best achieved with straight blades such as Miller blade and Truview laryngoscope. ${ }^{1}$ Arshad Z and colleagues compared laryngoscopic view and hemodynamic changes with flexi tip McCoy and Macintosh laryngoscope blade in predicted easy and difficult airway in a total of 220 patients and arrived at a conclusion that the McCoy blade may be a substitute of Macintosh blade in difficult airway cases, but not the substitute of Macintosh blade in every case. The McCoy blade improved laryngeal view in patients with limited neck extension. ${ }^{12}$ Katiyar A et al compared Truview and Macintosh laryngoscopes for ease of intubation in geriatric patients and concluded that Truview blade consistently provided better laryngoscopic view than using Macintosh blade for tracheal intubation, needed similar number of attempts for successful intubation and was associated with similar changes in hemodynamics. ${ }^{13}$ In our study the view of glottis was better in group I compared to group II and III ( $\mathrm{P}=0.024$ and $<0.0001$ respt.). However the view was better in group II compared to group III $(\mathrm{P}=0.036)$. The visualization is better with Truview due to presence of prismatic lens and optical appartatus providing a $42^{0}$ angled deflection view through a $15 \mathrm{~mm}$ eyepiece. ${ }^{1}$

A study compared the view obtained at laryngoscopy and intubating conditions of Truview (Group 1) or Macintosh (Group 2) blades in 170 patients who were scheduled to undergo general anesthesia. They studied preoperative airway evaluation, laryngoscopic view, duration of intubation, maximal force applied during intubation, anaesthetist's estimation of intubation effort on a 1-3 scale, bleeding, teeth and soft tissue damage, and postoperative stridor and hoarseness. The results demonstrated that whilst the Truview produced a better laryngoscopic view and less maximal force applied during intubation, the duration of intubation was longer. ${ }^{14}$ In a study where Truview blade was compared with Macintosh blade for laryngoscopy and intubation, visualization of the vocal cord, ease of intubation, time taken for intubation, number of attempts, 
and hemodynamic parameters were evaluated. The time taken for intubation was slightly more with Truview blade, while rest of the parameters were comparable. ${ }^{10}$

Altun D et al compared 4 Laryngoscopes Macintosh, McCoy, McGrath MAC and C-Mac in 2 difficult airway scenarios in a randomized crossover simulation based study. They found shortest intubation time with the Macintosh compared to others. ${ }^{15}$ In our study also the time for intubation was higher in group I compared to group II and III $(\mathrm{P}<0.0001$ and $\mathrm{P}<0.0001$ resp). Compared to group III there was significantly more time for intubation in group II $(\mathrm{P}<0.0001)$.Laryngoscopy and intubation is performed in an indirect manner with Truview,anaesthesiologists have to focus on vocal cord by seeing endotracheal tube on monitor. There is difficulty in advancing the tube towards the view of camera, making the intubation time longer with Truview. ${ }^{10}$

In a prospective randomized study, haemodynamic response to laryngoscopy and intubation between McCoy and Macintosh laryngoscope was studied in 100 patients. Mallampati grading, laryngoscopy and intubation time and laryngeal visualization grades were comparable. Increase in hemodynamic variables till 10 minutes post intubation was statistically significant with Macintosh laryngoscope as compared to McCoy. It was concluded that McCoy laryngoscope produces significantly less hemodynamic response as compared to Macintosh laryngoscope during laryngoscopy and intubation. ${ }^{16}$ Bag SK et al did a comparative study between Truview laryngoscope and Macintosh laryngoscope in terms of glottic opening, CLG, ease of intubation and hemodynamic parameters in two hundred patients undergoing elective surgery under general anaesthesia. The hemodynamic response to intubation was significantly less with the use of Truview laryngoscope when compared to that of Macintosh laryngoscope..$^{17}$ In our study the HR, MAP were comparable at T1, $2 \& 3$ intervals in all the three groups. The heart rate was comparable in group I and III at T 4, 5, 6, 7 but was higher in group I compared to group II at similar intervals, it was higher in group III compared to group II at T4, 5, 6 \& 7. MAP was higher in group I compared to group II at T4, 5, $6 \& 7$ but it was higher in group III compared to group I at T4, 5 \& 6 except at T7. The MAP was higher in group III compared to group II at T4, $5,6 \& 7$. The hinged tip blades controlled by a lever on the handle of McCoy laryngoscope allows elevation of epiglottis decreasing overall movement. This unique design has shown two advantages over Macintosh, the less force applied during laryngoscope and thus stress response is reduced. ${ }^{[18]}$ Even though Truview $\mathrm{PCD}^{\mathrm{TM}}$ applies minimal force while lifting anterior pharyngeal wall, the duration of laryngoscopy and intubation is prolonged compared to Macintosh.This significant difference in haemodynamic response can be attributed to increased intubation time and stimulation of pharynx for longer duration. ${ }^{19,20}$

\section{Conclusion}

Truview PCD TM laryngoscope blade could be an alternative in difficult airway situations where there is failure to visualize glottis with Macintosh and McCoy blades.
However it is not a substitute for intubation in every case as the time for intubation is longer and failure to intubate is slightly higher than the other two blades. This could probably be overcome by more experience, training and increase hand eye co-ordination.

\section{Conflict of Interest: None.}

\section{References}

1. Kulkarni AP, Tirmanwar AS. Comparison of glottic visualization and ease of intubation with different laryngoscope blades. Indian J Anaesth 2013;57:170-4.

2. Henderson JJ, Popat MT, Latto IP, Pearce AC. Difficult Airway Society guidelines for management of the unanticipated difficult intubation. Anaesth 2004;59:675-94.

3. Chandra A, Yathish SK, Gupta A, Agarwal DN, Chopra R. Oral premedicaton with pregabalin or clonidine for attenuating the pressor response to laryngoscopy and tracheal intubation in laparoscopic cholecystectomy. Med J DY Patil Vidyapeeth 2018;11:532-8.

4. Arora S, Sayeed H, Bhardwaj N. A comparison of Truview EVO2 laryngoscope with Macintosh laryngoscope in routine airway management: A randomized crossover clinical trial. Saudi J Anaesth 2013;7:244-8.

5. Cormack RS, Lehane J. Difficult tracheal intubation in obstetrics. Anaesth 1984;39:1105-11.

6. Levitan RM, Kinkle WC, Levin WJ, Everett WW. Laryngeal view during laryngoscopy: A randomized trial comparing cricoid pressure, backward-upward-rightward pressure, and bimanual laryngoscopy. Ann Emerg Med 2006;47:548-55.

7. Mallampati SR, Gatt SP, Gugino LD, Desai SP, Waraksa B, Freiberger D, et al. A clinical sign to predict difficult tracheal intubation: a prospective study. Can Anaesth Soc J 1985;32:429-34.

8. Macintosh RR.A new laryngoscope. Lancet 1943;1:205.

9. McCoy EP, Mirakhur RK. The levering laryngoscope. Anaesth 1993;48:516-9.

10. Timanaykar RT, Anand LK, Palta S. A randomized controlled study to evaluate and compare Truview blade with Macintosh blade for laryngoscopy and intubation under general anesthesia. J Anaesthesiol Clin Pharmacol 2011;27:199-204.

11. Arino JJ, Velasco JM, Gasco C, Lopez-Timoneda F. Straight blades improve visualization of the larynx while curved blades increase ease of intubation: A comparison of the Macintosh, Miller, McCoy, Belscope and Lee-Fiberview blades. Can J Anaesth 2003;50:501-6.

12. Arshad Z, Abbas H, Bogra J, Saxena S. Comparison of Laryngoscopic view and hemodynamic changes with flexi tip McCoy and Macintosh laryngoscope blade in predicted easy and difficult airway. Journal of Anesthesiology, 2013;3:27882.

13. Katiyar A, Jain S, Mehta RK, Kumar A, Agarwal A, Singh CS. Anaesthesia Update, ISA UP chapter 2013;16:33-8.

14. Barak M, Philipchuck P, Abecassis P, Katz Y. A comparison of the Truview blade with the Macintosh blade in adult patients. Anaesth 2007;62:827-31.

15. Altun D. Comparison of 4 Laryngoscopes in 2 Difficult Airway Scenarios: A Randomized Crossover SimulationBased Study. Simul Healthc 2016;11:304-8.

16. Singhal $S$ and Neha. Haemodynamic Response to Laryngoscopy and Intubation: Comparison Of McCoy And Macintosh Laryngoscope. Internet J Anesth 2007;17(1):1-5. 
17. Bag SK, Kumar VR, Krishnaveni N, Ravishankar M, Velraj J, Aruloli M. A comparative study between Truview laryngoscope and Macintosh laryngoscope in viewing glottic opening and ease of intubation; A crossover study. Anesth Essays Res 2014;8:372-6.

18. Uchida T, Hikawa Y, Saito Y, Yasuda K. The McCoy levering laryngoscope in patients with limited neck extension. Can J Anaesth 1997;44:674-6.

19. Kolli SN, Karnik HS, Parikh DA, Tendolkar BA. A Comparative Evaluation of Truview and Macintosh Laryngoscopes for Tracheal Intubation. Bombay Hospital J 2015;57:297-305.

20. Raveendra US, Mehandale SG, Shetty SR, and Kamath MR. Evaluation of the Truview ${ }^{\mathrm{TM}}$ EVO2 laryngoscope for nasotracheal intubation. Saudi J Anaesth 2012;6:398-402.

How to cite this article: Chandra A, Singh M, Agarwal M, Duggal R, Gupta D. Evaluation and comparison of haemodynamic response and ease of intubation between Truview PCD TM, McCOY and Macintosh laryngoscope blades. Indian J Clin Anaesth 2019;6(2):209-14. 